\title{
Hybrid Models of Studied Objects Using Remote Laboratories for Teaching Design of Control Systems
}

\author{
http://dx.doi.org/10.3991/ijoe.v12i09.6128 \\ M. Poliakov ${ }^{1}$, T.Larionova ${ }^{1}$, G. Tabunshchyk ${ }^{1}$, A. Parkhomenko ${ }^{1}$ and Karsten Henke ${ }^{2}$ \\ ${ }^{1}$ Zaporizhzhya National Technical University, Zaporizhzhya, Ukraine \\ ${ }^{2}$ Ilmenau University of Technology, Ilmenau, Germany
}

\begin{abstract}
This paper present models of studied objects with the help of remote laboratories containing physical and software components. These hybrid models were described as an integrated system with a hierarchy of controls. The functional structure of hybrid models was formalized using set theory. There are described examples of hybrid models, which software component contains subsystems of virtual models, models of the "hidden" part, the technical state models and environment models of the studied object. There are considered teaching scenarios of hybrid models application. It was given an example of design teaching scenario of diagnostic subsystem of a traffic light.
\end{abstract}

Index Terms-Hybrid models; integrated system; remote laboratory; set-theoretic model; teaching scenario of learning.

\section{INTRODUCTION}

Application field of remote laboratories (RL) [1-5] in the engineering education process is continuously expanding. Along with the subjects that study operation principles and calculation methods of technical devices, it is prospective to use RL in disciplines studying the design principles of these devices and systems based on them, including structure synthesis of these systems. At the same time in the RL for design learning specific teaching scenarios are used. Implementation of these scenarios complicates the structure and increases the complexity of the creation of these laboratories. In papers [6-13] it was considered issues related to functionality, application, diagnostic, added reality of RL models and others.

Absence of typical structural-functional models of studied objects in the known literature complicates its decomposition into subsystems for simplification of the laboratory design process. Therefore, development of the structural-functional models of studied objects presents urgent scientific and technical problem.

\section{INTEGRATED SYSTEMS AND STUDIED OBJECT MODELS}

Remote laboratories based on the results of scientifictechnical revolution obtained in the second half of the twentieth century in a number of scientific and technological areas (listed in Table I).

From such a wide application of scientific advances in $\mathrm{RL}$ naturally follows a conception that RL is an integrated system.

The structure of such a system evolves in the implementation of new teaching scenarios. This is particularly evident when using the RL in the learning process of control systems engineering design. The hierarchy of such systems is insufficiently studied and described in the literature, mainly in system-elemental aspect with relationships "whole-part".

In the paper control hierarchy is used for RL description. In concordance with control hierarchy in each subsystem, integrated in system, one defines sets of elements (control objects $(\mathrm{CO})$, control units $(\mathrm{CU})$ ) and sets of their relations (mutual and external). In some cases, CU is described by a finite state machine (FSM) model. At the same time CU in the $i^{\text {th }}$ hierarchy level subsystem may simultaneously be CO in subsystems of the $(i+1)^{\text {th }}$ and higher hierarchy levels. Taken together, these descriptions of all subsystems of the RL integrated system is called the set-theoretic model. More detailed descriptions of these models can be found in [15].

A significant part of RL subsystems presents different models of studied objects. In courses on control systems they are $\mathrm{CO}$ and $\mathrm{CU}$ models. We consider that studied objects has some functionality $\mathrm{F}_{\mathrm{SO}}$, which is inherited in physical $\left(\mathrm{F}_{\mathrm{PM}}\right)$, virtual $\left(\mathrm{F}_{\mathrm{VrM}}\right)$ and visual $\left(\mathrm{F}_{\mathrm{ViM} 1}, \mathrm{~F}_{\mathrm{ViM} 2}\right) \mathrm{RL}$ models. Inheritance structure is shown in Fig. 1.

TABLE I. APPLICATION OF THE SCIENTIFIC-TECHNICAL REVOLUTION RESULTS IN RL

\begin{tabular}{|l|l|}
\hline \multicolumn{1}{|c|}{ Scientific and technical area } & \multicolumn{1}{|c|}{ Application in RL } \\
\hline 1. Internet, personal computers, distributed systems & Remote real-time access to information resources and multimedia of RL \\
\hline $\begin{array}{l}\text { 2. Industrial automation: hardware (microcontrollers, industrial controllers } \\
\text { and network, sensors and actuators), software (human-machine interface, } \\
\text { emulators, programming environments), specialized automated systems } \\
\text { (measurement, control, diagnostics, trainers etc.) }\end{array}$ & $\begin{array}{l}\text { Components of control systems of physical models of study, research and } \\
\text { design objects; visual and virtual models of study objects; the structure of } \\
\text { software and hardware for design and experiments with physical and } \\
\text { virtual models }\end{array}$ \\
\hline $\begin{array}{l}\text { 3. Computer modeling, cybernetics, systems engineering, artificial intelli- } \\
\text { gence, automated design systems }\end{array}$ & Formal and virtual models of object and control unit top-level \\
\hline 4. Distance learning theory [14] & Learning scenario of RL aids \\
\hline
\end{tabular}




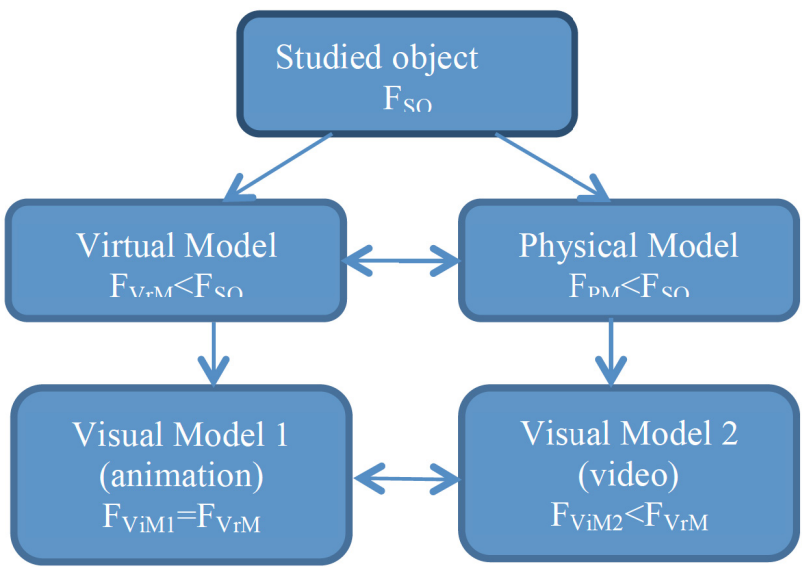

Figure 1. Structure of functionality research of studied object in RL models

The PM of CO contains electromechanics that is similar to the real object, but differs in parameters. Functionality of $\mathrm{CO}$ physical model is reduced $\left(\mathrm{F}_{\mathrm{PM}}<\mathrm{F}_{\mathrm{SO}}\right)$ due to the need to meet the requirements of the cost, size and power consumption decreasing. For example, a real elevator has load capacity $500 \mathrm{~kg}$, and a model $-0.5 \mathrm{~kg}$. Parameters of electromechanics differ correspondingly. The functionality of the CU physical model must comply with the functionality of the $\mathrm{CO}$ physical model. At the same time the PM of CU may has additional functionality, for instance, associated with the analysis of the student's project (application).

Virtual models include arithmetic and (or) logical expressions describing the behavior of $\mathrm{CO}$ as a finite state machine, a logical node, the system with transfer functions and others.
Virtual CO model in known RL has a reduced functionality of $\mathrm{CO}$, corresponding to functionality of a physical CO model. Below we will consider ways to expand the functionality of the virtual model and the sharing of the virtual and physical models (hybrid model).

The visual model presents video of $\mathrm{CO}$ or a set of graphic elements on the screen, attributes, location and appearance of which indicate the state and behavior of the physical and (or) virtual model of CO. Only visual models are available for students in the remote browser. An example of a visual model of the tank with liquid - graphical object of the tank outline; the level of the outline fill is proportional to the value corresponding to the program counter in the virtual model. The functionality of visual and virtual models must match each other. Photo- and video image of a physical CO model, obtained with the help of WEB-camera is also a visual model. Combination of visual models of the physical and virtual RL parts forms an image perceived by the student's sensors.

\section{RESUltS AND DiscusSION}

Based on the introduced definitions let's decompose designed RL into hybrid model, video and control mode subsystems, as shown in Fig. 2.

Video subsystem $\left(\mathrm{DS}_{2}\right)$ consists of video monitoring means $\left(\mathrm{CO}_{2}\right)$ and control unit $\left(\mathrm{CU}_{2}\right)$ of $\mathrm{CO}_{2} \cdot \mathrm{CO}_{2}$ controls selection of video camera, camera angle and illumination of PM. Despite the fact that the complexity of these devices is comparable or even higher than the complexity of the designed system standard technical solutions are used. Therefore, in this paper the system $\mathrm{DS}_{2}$ is not detailed.

Hybrid model includes systems: CO physical model $\left(\mathrm{DS}_{1}\right)$, four visual $\left(\mathrm{DS}_{3}-\mathrm{DS}_{6}\right)$ and four virtual $\left(\mathrm{DS}_{7}-\mathrm{DS}_{10}\right)$ models.

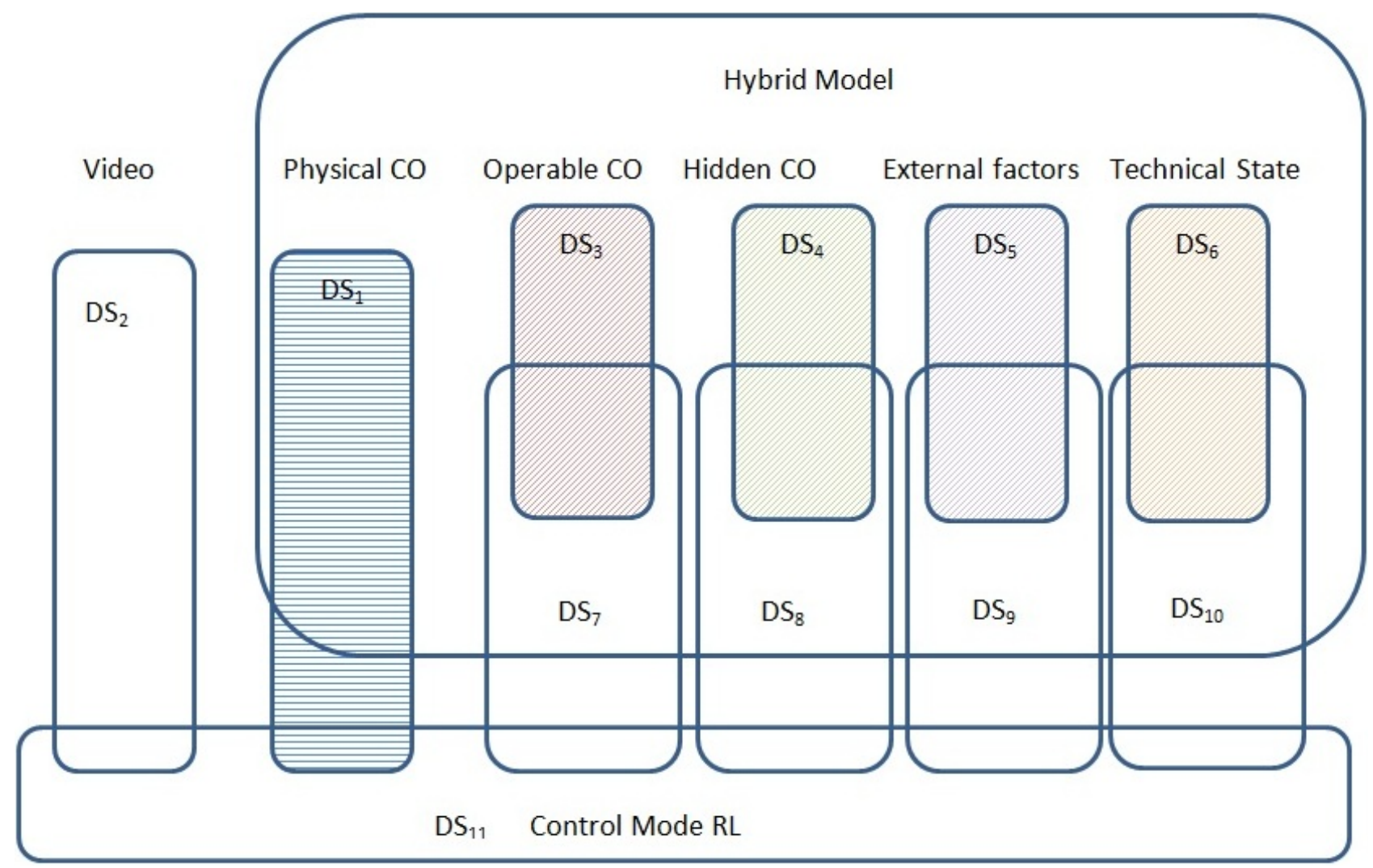

Figure 2. Decomposition of the RL integrated system 
System $\mathrm{DS}_{1}$ includes a control object $\mathrm{CO}_{1}$ and control unit $\mathrm{CU}_{1}$. In terms of $\mathrm{CU}_{1}$, object $\mathrm{CO}_{1}$ is a set of sensors and actuators. The outputs of the sensors $\mathrm{O}_{\mathrm{CO} 1}$ are inputs of $\mathrm{I}_{1 \mathrm{CU} 1}$, and inputs of $\mathrm{I}_{\mathrm{CO} 1}$ are connected to the outputs $\mathrm{O}_{1 \mathrm{CU} 1}$. As RL is usually operated only in the remote mode, among the $\mathrm{CO}_{1}$ output signals, buttons and other controls, which are used during operation of the real object, may be absent. Moreover in the electromechanics of model $\mathrm{CO}_{1}$ there are no elements used in emergency, abnormal operational mode of the real object. They can be modeled in the virtual model of other systems. Electromechanics of a physical model of the designed object is a control object from the RL, but at the same time - control unit from the mechanical part of this object.

The control unit $\mathrm{CU}_{1}$ processes the information $\mathrm{I}_{1 \mathrm{CU} 1}$, tag of the student control events $\mathrm{I}_{2 \mathrm{CU} 3}$ and generates control signals $\mathrm{O}_{1 \mathrm{CU} 1}$ by means of physical model $\mathrm{CO}_{1}$, sensor tags and states of physical model $\mathrm{O}_{2 \mathrm{CU}}$ for use by other systems.

Visual systems of operable $\left(\mathrm{DS}_{3}\right)$ and hidden $\left(\mathrm{DS}_{4}\right) \mathrm{CO}$ represents one or several graphics screens, each of which corresponds to a particular view of the system being designed, for example, a front view, from the inside, etc. The screens contain video of physical CO or graphical objects and virtual controls of the designed object and the video of a physical model of the object.

Graphical objects match the visible $\left(\mathrm{CO}_{3}\right)$ and hidden $\left(\mathrm{CO}_{4}\right)$ part of the physical model or studied objects. Graphical objects attributes, such as the coordinates on the screen, the rotation angle, color, width, percent of the figure fill and others change depending on the values of control tags. An example of hidden elements, i.e. the elements that are active in emergency or auxiliary modes of $\mathrm{CO}$ operation is a brake of the passenger elevator, which must actuate with the cable break.

In the system $\mathrm{DS}_{3}$ model $\mathrm{CU}_{3}$ plays the role of the control unit for the model $\mathrm{CO}_{3}$. The $\mathrm{CU}_{3}$ features include the formation of values of the control graphical objects tags, $\mathrm{CO}_{3}$ in the time function, events of student control, values of sensor tags and states of physical CO model. Block $\mathrm{CU}_{4}$ generates tag values, depending on the tag values of the actuators of the hidden part of virtual CO.

Visualization model of the external factors $\mathrm{DS}_{5}$ consist of visual model of the external factors $\left(\mathrm{CO}_{5}\right)$ and virtual model of visualization of the $\mathrm{CO}$ external factors $\left(\mathrm{CU}_{5}\right)$.

Elements of $\mathrm{CO}_{5}$ present graphical objects, which reflect the current values or the time history (trends) of corresponding tags. For example, the parameters of the power supply, ambient temperature, load current etc. $\mathrm{CU}_{5}$ elements represent calculation of graphical model of $\mathrm{CO}$ external factors dynamics. The inputs of the model are tags of external factors; outputs - control graphical objects tags of $\mathrm{CO}_{5}$ model and also generated flow of the control events. For example, at analysis of the passenger elevator capacity event flow of the elevator calls can be generated.

Visualization model of CO technical state $\mathrm{DS}_{6}$ consists of visual model of $\mathrm{CO}$ technical state $\mathrm{CO}_{6}$ and virtual model of $\mathrm{CO}$ technical state visualization $\left(\mathrm{CU}_{6}\right)$.

If the automaton model is taken as the technical state model, the elements of $\mathrm{CO}_{6}$ will present graphical objects that visualize the current status of the automaton - its tops and arc. Control graphical objects tags $\mathrm{CO}_{6}$ are formed by calculation graphical model $\mathrm{CU}_{6}$, which, in turn, is controlled by tags of $\mathrm{CO}$ technical state change.
On the second level of decomposition virtual models $\mathrm{DS}_{3}-\mathrm{DS}_{6}$ are supplemented with $\mathrm{CU}$ and form systems $\mathrm{DS}_{7}-\mathrm{DS}_{10}$. Systems of virtual models $\mathrm{DS}_{7}-\mathrm{DS}_{10}$ are formed from control objects $\mathrm{CO}_{7}=\mathrm{CU}_{3}, \mathrm{CO}_{8}=\mathrm{CO}_{4}$, $\mathrm{CO}_{9}=\mathrm{CO}_{5}, \mathrm{CO}_{10}=\mathrm{CO}_{6}$ and control units $\mathrm{CU}_{7}, \mathrm{CU}_{8}, \mathrm{CU}_{9}$, $\mathrm{CU}_{10}$.

$\mathrm{CU}_{7}$ is a control unit of the virtual model of the operable (operated in normal mode) design system. Model $\mathrm{CU}_{7}$ presents the control automaton that generates tags of actuators of virtual $\mathrm{CO}$ based on state tag values of $\mathrm{CO}$ physical and visual models, CO control event tags, control tags of modeling modes of the virtual CO. Examples of control tags of modeling modes: scale of model time, synchronization of behavior of physical and virtual models, accounting of the hidden part of the events $\mathrm{CO}$ and selection of control events source. The structure of the automaton $\mathrm{CU}_{7}$ is determined by student with the development and entering of the $\mathrm{CO}$ control algorithm description.

$\mathrm{CU}_{8}$ is a control unit of virtual model of the hidden part of the design system. Model $\mathrm{CU}_{8}$ presents control automaton similar to the model $\mathrm{CU}_{7}$.

$\mathrm{CU}_{9}$ is a control unit of virtual model of the external factors of the design system. Model $\mathrm{CU}_{9}$ is an automaton which controls scenario of $\mathrm{CO}$ external factors changes by forming the tag values of external factors parameters. For example scenarios of changes in CO load and the intensity of it use.

$\mathrm{CU}_{10}$ is a control unit of virtual model of the technical state of the design system. Model $\mathrm{CU}_{10}$ is the automaton that initiates the events of defects appearing in the $\mathrm{CO}$ and adjusts the intensity of their development. For example, the event of parametric failure of the cooling system changes the $\mathrm{CO}$ technical state.

Control object $\mathrm{CO}_{11}$ of control system of RL modes $\mathrm{DS}_{11}$ is logically connects $\mathrm{CU}$ of the system $\mathrm{DS}_{1}, \mathrm{DS}_{2}$, $\mathrm{DS}_{7}-\mathrm{DS}_{10}$. Model $\mathrm{CU}_{11}$ is a control unit of RL modes. $\mathrm{CU}_{11}$ is the automaton that controls the starting and stopping of automatons belonging to $\mathrm{CO}_{11}$, changes the composition of their states, inputs and outputs, thereby implementing various teaching scenarios of RL application.

With the capabilities of RL hardware and software the occurrence of various RL teaching scenarios is associated. Let's describe existing and future scenarios in terms of objectives, the initial data, performed tasks, used models and obtained results.

I. Scenario 1. Objective: study of the programming, formalization methods of the control algorithms. Initial data: sensors and actuators of $\mathrm{CO}$, verbal description of the desired behavior of operable $\mathrm{CO}$ excluding effects of unobserved variables. Performed tasks: to formalize the $\mathrm{CO}$ behavior with the selected method, introduce the formalized description, monitor the implementation and, if necessary, correct the description. Used models: $\mathrm{CO}_{1}$, $\mathrm{CO}_{3}$. Example: industrial cell RL the Grid of Online Laboratory Devices Ilmenau (GOLDi) [16].

Scenario 2. Objective: study (to determine the structure and behavior) of $\mathrm{CO}$ by monitoring its operation. Initial data: video surveillance at $\mathrm{CO}$ model operation according to the reference control algorithm. Performed tasks: determining of the composition of $\mathrm{CO}$ sensors and actuators, verbal description of the desired behavior of the operable CO. Used models: $\mathrm{CO}_{1}, \mathrm{CO}_{2}$. Example: almost all physical models of RL GOLDi. 
Scenario 3. Objective: study of CO by remote experiments with $\mathrm{CO}$ inputs by students. Initial data: during the experiments the student set necessary for him values of $\mathrm{CO}$ inputs. Used models: $\mathrm{CO}_{1}, \mathrm{CO}_{3}$. Example: elevator of RL GOLDi.

Scenario 4. Objective: to study the completeness of developed by student $\mathrm{CO}$ control algorithms using benchmarks of $\mathrm{CO}$ inputs changes. Initial data: a benchmark set (BS), i.e., test containing the reference sequences of $\mathrm{CO}$ inputs changes, execution of which guarantee student algorithms check. Performed tasks: determining of the composition of $\mathrm{CO}$ sensors and actuators, verbal description of the desired behavior of the operating $\mathrm{CO}$. Used models: $\mathrm{CO}_{1}-\mathrm{CO}_{3}, \mathrm{CO}_{5}, \mathrm{CO}_{6}$. Example: elevator of $\mathrm{RL}$ GOLDi.

In the extended scenario version it is provided automatic diagnosis of student algorithms and the formation of a BS subset that reveal the incorrectness or incompleteness of student algorithms. Benchmarks can include inadmissible in normal operating states CO input data sets, leading to an emergency or destruction of $\mathrm{CO}$. In this case, they are executed only on the $\mathrm{CO}$ software simulator.

Scenario 5. Objective: to study design methods of control and diagnostic tests of $\mathrm{CO}$ and control algorithms. Initial data: verbal description of the standard control algorithm, a list of possible CO faults, a program with the $\mathrm{CO}$ control algorithm, a set of uncontrollable inputs (effects of the external environment and internal changes in $\mathrm{CO})$. Performed tasks: development of control and diagnostic tests of $\mathrm{CO}$ and control algorithms. Used models: $\mathrm{CO}_{1}-\mathrm{CO}_{6}$, models of the faults dynamics. Example: elevator of RL GOLDi.

Scenario 6. Objective: design of CO control algorithms, (taking into account the abnormal input actions and possible faults in the CO. Initial data: the same as for Scenario 5. Performed tasks: development of control algorithms based on $\mathrm{CO}$ abnormal input actions and possible faults in the $\mathrm{CO}$, evaluation of their performance of the developed algorithms on RL models. Used models: $\mathrm{CO}_{1}-\mathrm{CO}_{10}$. Example: elevator of RL GOLDi.

Scenario 7. Objective: obtaining of $\mathrm{CO}$ operator skills. Initial data: $\mathrm{CO}$ model with control programs, objectives, control functional, flow of values on the inputs destabilizing the $\mathrm{CO}$ operation. Performed tasks: changes in $\mathrm{CO}$ monitored inputs during the control algorithm execution to maximize the value of the control functional. Used models: $\mathrm{CO}_{1}-\mathrm{CO}_{10}$. Example: simulator of the vehicle.

Proposed above decomposition principles of the integrated RL into systems let's consider in the example of the "elevator" model of GOLDi laboratory, which image is shown in Fig. 3.

Structure of physical (model $\mathrm{CO}_{1}$ ) and visual (model $\mathrm{CO}_{3}$ ) $\mathrm{CO}$ model is shown in Table II and III respectively.

Referencing of elements of $\mathrm{CO}_{1}$ model to physical model variables is presented on RL GOLDi site.

Elements of the visual model $\mathrm{CO}_{3}$ consist of graphical objects, some of which has animated control by the tags of virtual model $\mathrm{CO}_{7}$. So graphical objects "Cabin" which is grouped with graphical objects "Door" has control "vertical position". Graphical objects "Lamp of Cabin State" has control "color" from the variable of corresponding position sensor and so on.

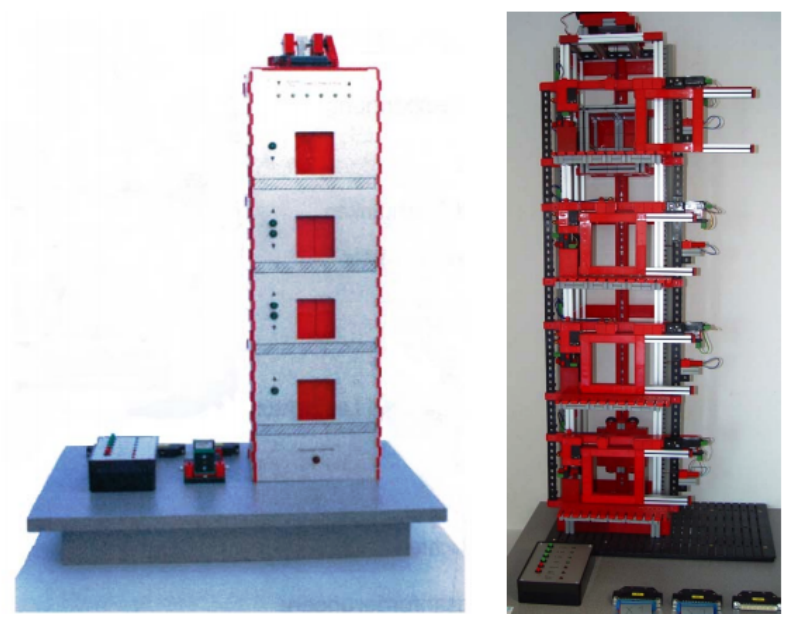

Figure 3. Physical models "elevator of the $4^{\text {th }}$ floors" at GOLDi laboratory

TABLE II.

STRUCTURE OF THE MODEL $\mathrm{CO}_{1}$

\begin{tabular}{|l|l|l|l|}
\hline \multicolumn{1}{|c|}{ Assembly } & \multicolumn{1}{|c|}{ Element } & \multicolumn{1}{|c|}{$\begin{array}{r}\text { Type of actuator } \\
\text { control }\end{array}$} & $\begin{array}{c}\text { Sensor } \\
\text { output }\end{array}$ \\
\hline $\begin{array}{l}\text { Mechanism } \\
\text { of the cabin } \\
\text { elevator }\end{array}$ & Electric motor & Up/down & \\
\hline \multirow{4}{*}{ Cabin } & Door mechanism & To open/close & \\
\cline { 2 - 5 } & Door sensors & & On/off \\
\cline { 2 - 5 } & Lamps in cabin & To switch on/off & \\
\cline { 2 - 5 } & Buttons in cabin & & On/off \\
\hline \multirow{3}{*}{ Floor } & Position sensor & & On/off \\
\cline { 2 - 5 } & Lamps on the floor & To switch on/off & \\
\cline { 2 - 5 } & Call buttons & & On/off \\
\hline
\end{tabular}

TABLE III.

STRUCTURE OF THE MODEL $\mathrm{CO}_{3}$

\begin{tabular}{|l|l|l|}
\hline \multicolumn{1}{|c|}{ Assembly } & \multicolumn{1}{|c|}{ Graphical object } & \multicolumn{1}{c|}{ Tag/control type } \\
\hline \multirow{5}{*}{ Building } & Building & - \\
\cline { 2 - 3 } & Cabin & $\begin{array}{l}\text { Cabin position/vertical dis- } \\
\text { placement }\end{array}$ \\
\hline \multirow{5}{*}{ Cabin } & Door & $\begin{array}{l}\text { Door position/horizontal dis- } \\
\text { placement }\end{array}$ \\
\cline { 2 - 4 } & Lamp & Lamp state/color \\
\cline { 2 - 3 } & Button & $\begin{array}{l}\text { Button state/ assignment of the } \\
\text { value to tag }\end{array}$ \\
\hline \multirow{3}{*}{ Floor } & Lamp & $\begin{array}{l}\text { Lamp state/color } \\
\text { Button state/ assignment of the } \\
\text { value to tag }\end{array}$ \\
\cline { 2 - 3 } & Button &
\end{tabular}

Elements of visual model of the hidden part of the virtual elevator $\left(\mathrm{CD}_{4}\right.$ model) include, for example, graphical objects which displays the temperature of the electric motor of the cabin drive, the position of the elements of the emergency control and state of the cable tension sensor.

Elements of visual model of the external factors dynamics (model $\mathrm{CO}_{5}$ ) are graphical objects of type "trend", reflecting the change of the external factors variables in the coordinates of model time. That may be the ambient temperature, the flow of elevator calls from the floors. 
Elements of the visual model of the technical state (model $\mathrm{CO}_{6}$ ) reflect the current number of no-fault cable strands, the remaining service life of the elevator equipment, elevator FSM graph.

Elements of the virtual model of the elevator $\left(\mathrm{CO}_{7}\right)$ convert values of variables of other RL models in graphical objects control parameters of model $\mathrm{CO}_{3}$. For example, the value of "moving up" and displacement time are transformed into the tag value "vertical position of the cabin".

Examined structure of the models are created by the RL server for each pair of "laboratory model (physical or virtual) - remote student".

One more example of the RL integrated system is scenario 6 implementation for model Traffic Light, included in Remote Laboratory for Embedded Systems Design (RELDES) $[10,17]$. Scenario steps are presented in Table IV.

At the $1^{\text {st }}$ step it is proposed to choose type of diagram $\mathrm{CO}_{1}$, which differs in polarity, mutual position LED and resistors, power source pole. Let $\mathrm{CO}_{1}$ diagram shown in Fig. 4 is chosen.

TABLE IV.

SCENARIO 6 STEPS FOR MODEL “TRAFFIC LIGHT”

\begin{tabular}{|c|c|}
\hline Step & Solution variant \\
\hline $\begin{array}{l}\text { 0. Statement of the main } \\
\text { task of traffic light model } \\
\text { (on LED indicators) } \\
\text { control }\end{array}$ & $\begin{array}{l}\text { Infinite loop with red, yellow, green, } \\
\text { yellow phases, duration of which are given } \\
\text { by constants }\end{array}$ \\
\hline $\begin{array}{l}\text { 1. Choice of main task } \\
\text { solution principles }\end{array}$ & $\begin{array}{l}\text { Logic level generation on control board } \\
\text { digital output for each LED with taking } \\
\text { into account LED connection and its light } \\
\text { time duration. So, if LED is connected } \\
\text { according to common-cathode circuit - } \\
\text { HIGH level for the light (ON state) and the } \\
\text { level of LOW - for quenching (OFF state) }\end{array}$ \\
\hline $\begin{array}{l}\text { 2. Formalization LED } \\
\text { state control sequences for } \\
\text { solution of the main } \\
\text { design task }\end{array}$ & Design of system FSM graph \\
\hline $\begin{array}{l}\text { 3. Analysis of possible } \\
\text { system faults, system } \\
\text { behavior at emergences } \\
\text { and actions required for } \\
\text { fault detection }\end{array}$ & $\begin{array}{l}\text { Critical defect - any break in circuit "board } \\
\text { output - LED - resistor - power supply". } \\
\text { System behavior - wrong indication. } \\
\text { Actions - voltage control of ON state LED, } \\
\text { failure indication }\end{array}$ \\
\hline $\begin{array}{l}\text { 4. Correction of electric } \\
\text { circuit and system behav- } \\
\text { ior, taking into account the } \\
\text { problem of possible } \\
\text { failures detection }\end{array}$ & $\begin{array}{l}\text { Choice of a diagram provided voltage } \\
\text { measurement across the circuit section with } \\
\text { LED and additional LED ERROR. Intro- } \\
\text { duction of additional states in the FSM } \\
\text { graph, for example, state ERROR }\end{array}$ \\
\hline $\begin{array}{l}\text { 5. Simulation of LED } \\
\text { defects during system } \\
\text { operation time }\end{array}$ & $\begin{array}{l}\text { Replacing in a certain time moment HIGH } \\
\text { level to LOW level at the output of the } \\
\text { control board, which controls the LED or } \\
\text { turn-off of the transistor, which is in-series } \\
\text { with LED. Development of FSM graph for } \\
\text { defects simulation }\end{array}$ \\
\hline $\begin{array}{l}\text { 6. Development of set- } \\
\text { theoretic models of local } \\
\text { subsystems for design task }\end{array}$ & $\begin{array}{l}\text { Development } \mathrm{CO}_{1}, \mathrm{CU}_{1} \text { with } \mathrm{FSM}, \mathrm{DS}_{1} \\
\mathrm{CO}_{4}, \mathrm{CU}_{4}, \mathrm{DS}_{4}, \mathrm{CO}_{6}, \mathrm{CU}_{6}, \mathrm{DS}_{6}\end{array}$ \\
\hline $\begin{array}{l}\text { 7. Implementation of } \\
\text { design task set-theoretic } \\
\text { models of local subsys- } \\
\text { tems in RL on the basis of } \\
\text { units with computing } \\
\text { power }\end{array}$ & $\begin{array}{l}\text { Implementation of local subsystems in the } \\
\text { control program of the microprocessor }\end{array}$ \\
\hline
\end{tabular}

At the $2^{\text {nd }}$ scenario step for the main control task graph FSM CU ${ }_{1}$ is designed (see Fig 5).

After choice of the critical defect (step 3) correction of the diagram $\mathrm{CU}_{1}$ is carried out (instead of diagram in Fig 4. diagram shown in Fig.6 with voltage measuring circuits and failure indication is chosen and designed).

System $\mathrm{DS}_{1}$ is presented in Fig.7, where DO is digital output pin; AI is analog input pin of the microprocessor board. Changes in $\mathrm{DS}_{1}$ structure are designed (imaged) in FSM graph (Fig.8) by addition of additional states ErrorRYG, ErrorE and event transfers ErrorR, ErrorY, ErrorG, ErrorE. These events are the evaluation result of the LED voltage measuring, for example:

$$
\text { ErrorR }=\left(\text { TestR }<\mathrm{U}_{\mathrm{LEDmin}}\right) \&\left(\mathrm{DO}_{1}=\mathrm{ON}\right),
$$

where $U_{\text {LEDmin }}$ is digital code of the minimal voltage on faultless LED in ON state.

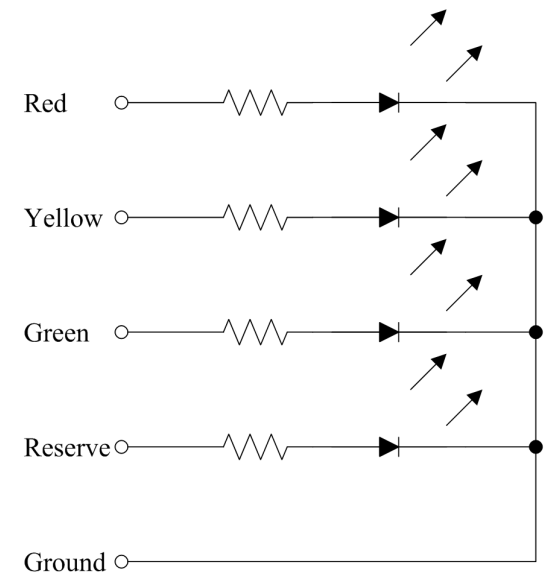

Figure 4. Model $\mathrm{CO}_{1}$ "Traffic Light"

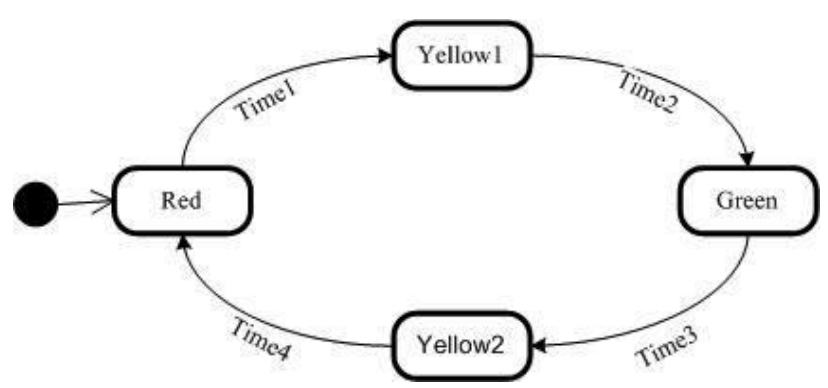

Figure 5. FSM graph $\mathrm{CU}_{1}$ for the main task of the traffic light

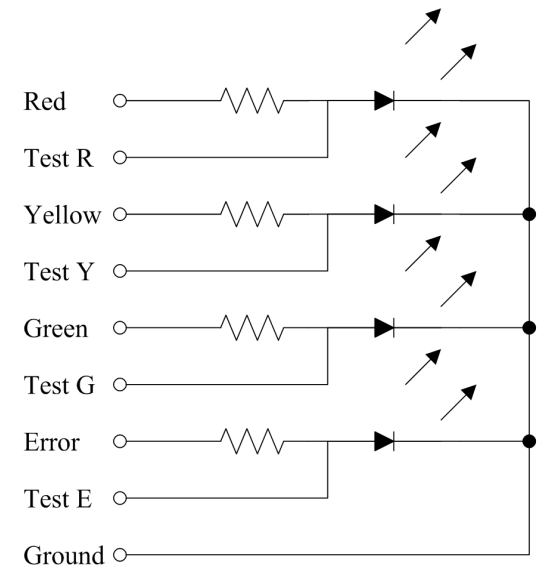

Figure 6. Model $\mathrm{CO}_{1}$ "Traffic Light" with LED voltage measuring circuits 


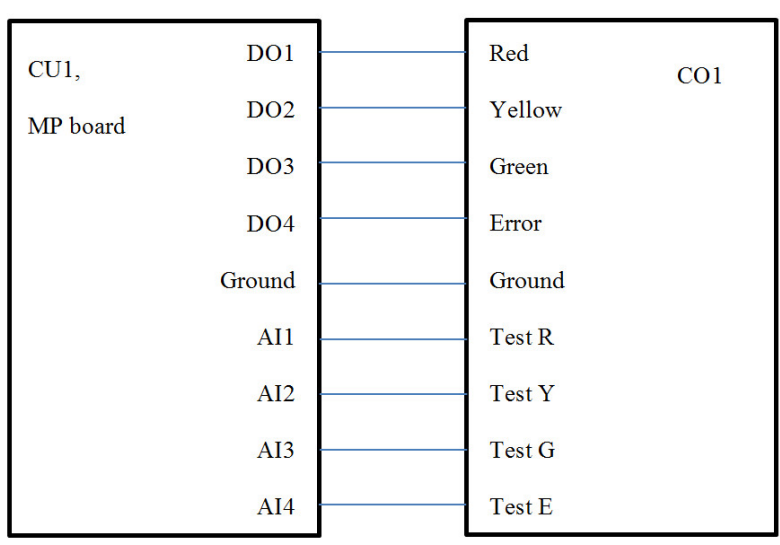

Figure 7. Model DS 1 "Traffic Light"

The state ErrorE is introduced to represent the situation when both are faulty, at least one of Red, Green, Yellow LED and the LED "Error".

FSM CU $\mathrm{CU}_{1}$ can be defined in a similar form:

$$
<\mathrm{X}, \mathrm{Y}, \mathrm{S}, \mathrm{S}_{0}, \mu, \sigma>\text {, }
$$

where $\mathrm{X}, \mathrm{Y}, \mathrm{S}$ is set of inputs (event), outputs and states of FSM $\mathrm{CU}_{1}$ correspondingly; $\mathrm{S}_{0}$ is initial state; $\mu$ is matrix of outputs $\sigma-$ matrix of transfers;

$\mathrm{X}=\{$ Time1, Time2, Time3,Time4, ErrorR, ErrorY, ErrorG, ErrorE\};

$$
\mathrm{Y}=\left\{\mathrm{DO}_{1}, \mathrm{DO}_{2}, \mathrm{DO}_{3}, \mathrm{DO}_{4}\right\}
$$

$\mathrm{S}=\{$ Red, Yellow1, Green, Yellow2, ErrorRYG, ErrorE $\}$;

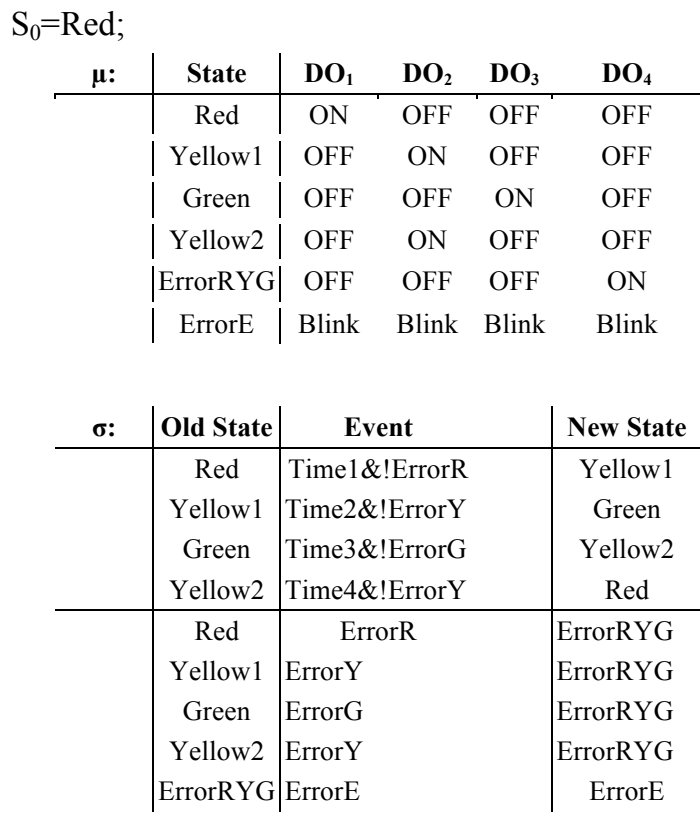

Where "!" is inversion sign; Blink is blinking mode of outputs - indication method of the LED (Red or Yellow or Green) failure at simultaneous LED Error failure.

RL RELDES peculiarity is absence of simulation screens of the system operation. Correctness of the designed system is checked visually by the image, obtained from WEB-camera (subsystem $\mathrm{DS}_{2}$ ). That's why model $\mathrm{DS}_{3}$ is not considered. Another RELDES peculiarity is that there are no computational nodes for implementation of $\mathrm{DS}_{4}$ model in RL system. Therefore $\mathrm{DS}_{4}$ (hidden part

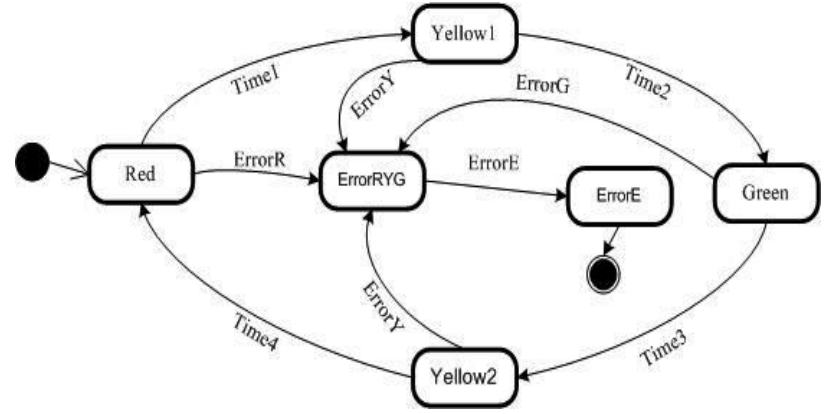

Figure 8. FSM graph $\mathrm{CU}_{1}$ for the traffic light with LED test

of $\mathrm{CO}_{1}$ ) functions should be taken into consideration in physical model diagram, for example as it is shown in Fig. 6.

$\mathrm{DS}_{6}$ (failure generation) functions is implemented in control program, executed on the microprocessor board.

For this purpose on formed by FSM value of inputs states are imposed. For example for input:

$$
\mathrm{DO}_{1}=\mathrm{DO}_{1} \& \text { ! genErr, }
$$

where genErr is failure simulation attribute.

If genErr $=\mathrm{ON}$ is assumed that LED transferred into failure state and $\mathrm{DO}_{1}$ possesses the value OFF irrespective of the value, formed by FSM. For genErr generation e.g. number of infinite control program operation loop can be used. Fragments of the sketch control the traffic light with function of LED failure detection is presented in Fig. 9.

\section{CONCLUSIONS}

1. RL functional structure and studied objects models used in it are important descriptive elements of the RL properties and features. The structure of the models, their variants, properties, studied objects functionality inheritance should be determined at the IEEE level in RL.

2. Analysis of the functional elements of a remote lab in coordinates "control object - control unit" showed that some elements function as the control object in one local system, and the control device in the other. Set-theoretic models of studied objects physical, virtual and visual models describe RL as an integrated control system.

3. It was proposed to extend the studied objects hybrid model in RL. To known structure it was added a subsystem of a "hidden" part, studied objects technical state and environment, which interact with studied objects physical and virtual models. These additions increase the functionality of studied objects model, which allows setting more complex design tasks for students and increasing a number of experiments with physical models without their modification.

4. Taking into account the additional possibilities of hybrid models it was offered additional scripts of RL usage. To the basic scenario "programming of logic control algorithms of serviceable studied objects" it was added: "definition of the studied objects structure and state by monitoring of its operation", "experiments with actuators of studied objects physical virtual model", "check of studied objects control algorithms using tests", "development of studied objects verificatory and diagnostic tests", "development of control algorithms for studied objects emergency operation" and "operator's simulator". 


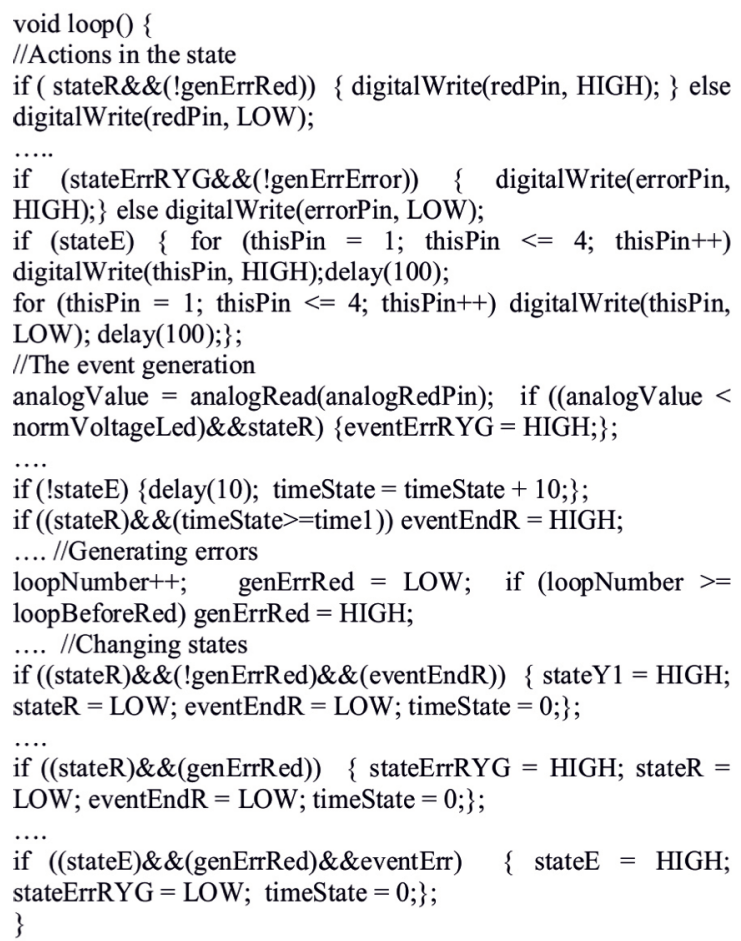

Figure 9. Fragments of the sketch control the traffic lights with function of LED failure detection

5. The usefulness of the hybrid model of the studied object shown in the example scenario of teaching design of the traffic light. In this scenario, the functionality of a traditional physical model of the traffic lights (indication LED Red/Yellow/Green) complemented by diagnostics of the technical condition of LED. Hidden $\mathrm{CO}$ and State Technical subsystems included in a hybrid model of traffic lights for the implementation of this function.

These scenarios are supposed to be used for the design of remote laboratories in Zaporizhzhya National Technical University as a part of international program "Tempus" ICo-op for creation of the training courses for distance engineering education in the directions "Electromechanics" and "Software Engineering" based on remote engineering and virtual instruments $[3,18]$.

\section{REFERENCES}

[1] A.K.M. Azad, M.E. Auer, and V.J. Harward, Eds. (2012) Internet Accessible Remote Laboratories: Scalable E-Learning Tools for Engineering and Science Disciplines, Engineering Science Reference, $645 \mathrm{p}$.

[2] C. Gravier and et al., "State of the Art About Remote Laboratories Paradigms - Foundations of Ongoing Mutations," Int. J. of Online Engineering (iJOE), vol. 4, no. 1, pp. 1-9, 2008.

[3] Remote and virtual tools in engineering: monograph / general editorship Karsten Henke (2015), Dike Pole, Zaporizhzhya, Ukraine, 250p. ISBN 978-966-2752-74-8.

[4] Instructional-design Theories and Models A New Paradigm of Instructional Theory, Volume II Edited by Charles M. Reigeluth (C) 1999 - Routledge. 728 p.

[5] L. Gomes and S. Bogosyan, "Current trends in remote laboratories," Industrial Electronics, IEEE Transactions on, vol. 56, no. 12 , pp. 4744- 4756, 2009. http://dx.doi.org/10.1109/TIE. 2009.2033293

[6] Y. Toyoda, N. Koike, Y. Li. An FPGA-based Remote Laboratory: Implementing Semi-Automatic Experiments in the Hybrid Cloud// International Conference on Remote Engineering and Virtual Instrumentation, REV2016, Madrid, Spain, February 24-26, 2016, pp.18-23.

[7] C. Terkowsky, I. Jahnke, C. Pleul, R. Licari, P. Johannssen, G. Buffa, M. Heiner, L. Fratini, E. Lo Valvo, M. Nicolescu, J. Wildt
\& A.E. Tekkaya, (2010) "Developing Tele-Operated Laboratories for Manufacturing Engineering Education. Platform for ELearning and Telemetric Experimentation (PeTEX)," in: International Journal of Online Engineering (iJOE), Vol.6 Special Issue 1: REV2010, Vienna, IAOE, pp. 60-70. http://dx.doi.org/10.3991/ ijoe.v6s1.1378

[8] A.M. Maiti, A.A. Kist, A.D. Maxwell Variable Interactivity with Dynamic Control Strategies in Remote Laboratory Experiments// International Conference on Remote Engineering and Virtual Instrumentation, REV2016, Madrid, Spain, February 24-26, 2016, pp.399-407

[9] L. F. Zapata Rivera M. M. Larrondo-Petrie Models of Remote Laboratories and Collaborative Roles for Learning Environments// International Conference on Remote Engineering and Virtual Instrumentation, REV2016, Madrid, Spain, February 24-26, 2016, pp.408-414.

[10] A. Parkhomenko, O. Gladkova, E. Ivanov, A. Sokolyanskii, S. Kurson "Development and Application of Remote Laboratory for Embedded Systems Design” iJOE - Volume 11, Issue 3, 2015, pp. 27-31.

[11] K. Henke, St. Ostendorff, H.-D. Wuttke, T. Vietzke, Ch. Lutze, "Fields of Applications for Hybrid Online Labs", International Journal of Online Engineering (iJOE), Vol 9 (2013); pp. 20-30, Vienna, May 2013. http://dx.doi.org/10.1109/rev.2013.6502899

[12] A. Maiti, A.A. Kist and A. Maxwell Variable Interactivity with Dynamic Control Strategies in Remote Laboratory Experiments// International Conference on Remote Engineering and Virtual Instrumentation, REV2016, Madrid, Spain, February 24-26, 2016, pp.399-407.

[13] Marin Vlada, Grigore Albeanu The Potential of Collaborative Augmented Reality in Education //The $5^{\text {th }}$ International Conference on Virtual Learning ICVL'2010. /TARGU - MUREŞ, ROMANIA, 29 - 31 oct., 2010, pp.39-43.

[14] Moore M. G. Handbook of Distance Education. The Pennsylvania State University, 2007. $690 \mathrm{p}$.

[15] M. Poliakov, T. Larionova, G. Tabunshchyk, A. Parkhomenko, K. Henke. Remote laboratory for teaching of control systems design as an integrated system// International Conference on Remote Engineering and Virtual Instrumentation, REV2016, Madrid, Spain, February 24-26, 2016, pp.333-340.

[16] GOLDi-labs cloud Website: http://goldi-labs.net

[17] RELDES. http://swed.zntu.edu.ua, http://youtu.be/u2anq--UYFg

[18] ICo-op project Website: http://www.ICo-op.eu

\section{AUTHORS}

Mykhailo Poliakov, is with Zaporizhzhya National Technical University, Electrical and Electronic Apparatuses Department, Zhukovskogo, 64, Zaporizhzhya, 69063 Ukraine. (e-mail: polyakov@zntu.edu.ua).

Tetiana Larionova, is with Zaporizhzhya National Technical University, Electrical and Electronic Apparatuses Department, Zhukovskogo, 64, Zaporizhzhya, 69063 Ukraine. (e-mail: newweb.author@gmail.com).

Galyna Tabunshchyk is with the Zaporizhzhya National Technical University, Software Tools Department, Zhukovskogo 64, Zaporizhzhya, 69063 Ukraine, (e-mail: galina.tabunshchik@gmail.com).

Anzhelika Parkhomenko is with the Zaporizhzhya National Technical University, Software Tools Department, Zhukovskogo 64, Zaporizhzhya, 69063 Ukraine, (email: parhom@zntu.edu.ua).

Karsten Henke is with Ilmenau University of Technology, Ilmenau, Germany. (e-mail: karsten.henke@tuilmenau.de).

This work was supported the European Commission within the program "Tempus", "ICo-op - Industrial Cooperation and Creative Engineering Education based on Remote Engineering and Virtual Instrumentation", Grant No 530278-TEMPUS-1-2012-1-DE-TEMPUS-JPHES.

This article is an extended and modified version of a paper "Remote laboratory for teaching of control systems design as an integrated system" presented at the International Conference on Remote Engineering \& Virtual Instrumentation (REV2016), held in Madrid, Spain, February 24-26, 2016.

Submitted 08 August 2016. Published as resubmitted by the authors 10 September 2016. 